DOI: $10.17805 /$ zpu.2015.2.20

\title{
Лирика Г. Тукая в межлитературном контексте
}

\author{
B. Р. АМИНЕВА
}

\author{
(КАЗАНСКИЙ (ПРИВОЛЖСКИЙ) ФЕДЕРАЛЬНЫЙ УНИВЕРСИТЕТ)
}

На материале лирики татарского поэта Г. Тукая (1886-1913) и русских поэтов ХІХ в. (А. С. Пушкина, М. Ю. Лермонтова, Н. А. Некрасова) устанавливаются виды диалогических отношений между текстами, принадлежащими разным национальным литературам: "“свое" как переструктурированное "чужое"”, “"свое” как противопоставленное "чужому"», “"свое”, сходное с "чужим"». Раскрывается генеративная функция межлитературных диалогов как фактора, под влиянием которого происходят сдвиги в эстетическом сознании и совершаются изменения в культуре художественного творчества. 
В диалоге с русской литературой XIX в. в лирике Г. Тукая формируется новый творческий принцип, характерный для поэтики модальности. Этот принцип проявляется во всех архитектонических формах эстетического объекта, прежде всего в субъектной сфере произведений. В лирике Г. Тукая можно констатировать рождение разных типов лирического субъекта - лирического «Я», лирического героя, героя ролевой лирики, субъектного неосинкретизма как результата самоидентификации «Я». Формы выражения авторского сознания, складывающиеся в творчестве Г. Тукая и русских поэтов, определяют жанрово-стилистические особенности их произведений. Лиризм нового типа подготавливает переход и к новым принципам жанрового самоопределения. В творчестве Г. Тукая наряду с синтетическими методами изображения внутреннего мира человека широко используются аналитические приемы психологизма, ориентированные на воссоздание внутреннего мира человека нового времени.

Таким образом, диалог Г. Тукая с русскими поэтами XIX в. позволяет выявить интегративные процессы в сопоставляемых литературах, с одной стороны, и раскрыть их национальную идентичность - с другой.

Ключевые слова: русская литература, татарская литература, Г. Тукай, межлитературный диалог, лирическая поэзия, национальная художественная эстетика.

\section{BВЕАЕНИЕ}

$\mathrm{B}$ отечественной и зарубежной науке существует мнение, что компаративистика вышла за рамки традиционных сопоставлений и противопоставлений отдельных культур и литератур во времени и пространстве и переходит от концепции «всеобщей мировой литературы» (И. Г. Гете) к идее понимания «Аругого». Аальнейшая разработка теории сравнительного литературоведения связана с расширением его проблемного поля - переходом к широкому кругу гносеологических, культурологических, аксиологических и других проблем. Общенациональными и внутриэтническими причинами вызвана потребность в компаративистских исследованиях, сконцентрированных на проблемах национального литературного процесса и ориентированных на выявление идентичности национальных литературно-художественных систем.

В работе «К методологии гуманитарных наук» М. М. Бахтин, поставив проблему «контекстов понимания» и разграничив малое время современности и большое время, «близкий» и «далекий» контексты, пишет о нескончаемом обновлении смыслов во все новых контекстах (Бахтин, 1979: 372). В качестве такого «контекста понимания» русской литературы XIX в. (поэзии А. С. Пушкина, М. Ю. Аермонтова, Н. А. Некрасова) в нашем исследовании выступает творчество татарского поэта Г. Тукая (1886-1913), являющееся своеобразным диалогизирующим фоном ее восприятия. Русская классика XIX в. осознается татарским поэтом как «полноправный субъект», реальный и конкретный «Аругой», участвующий в концептуализации своего слова о мире и человеке. Вместе с тем поэзия Г. Тукая - сложная идейно-эстетическая система, в которой на разных уровнях и в разных формах осуществляется диалог восточно-национальных, русско-европейских и народных традиций. Этот диалог становится содержательно и структурно обязательным в творчестве татарского поэта.

Тема «Г. Тукай и русская литература» исследуется в разных аспектах. Так, в монографии И. Г. Пехтелева «Тукай и русская литература» содержатся объяснение и оценка тех сторон творчества татарского поэта, которые органически связывают его с русской литературой. Сходство эстетической позиции Г. Тукая и А. С. Пушкина, Г. Тукая и М. Ю. Аермонтова, Г. Тукая и Н. А. Некрасова ученый объясняет контактными связями - фактом влияния (Пехтелев, 1966: 15-16, 102-103, 117). Существующие между творчеством Г. Тукая и русских поэтов XIX в. контактно-генетические связи и типологические схождения формируют разные типы диалогических отноше- 
ний между ними: «“свое” как переструктурированное “чужое”», «“свое” как противопоставленное “чужому”», «свое”, сходное с “чужим”» и др. В них проявляются основные тенденции национального культурно-исторического развития, обнаруживается действие дивергентных и конвергентных связей, формирующих концептуальносемиотическое пространство межлитературного процесса.

\section{СУБЪЕКТНАЯ СФЕРА АИРИКИ Г. ТУКАЯ}

Поэтика, характерная для традиционалистского типа сознания, в лирике Г. Тукая трансформируется под влиянием нового художественного принципа, который формируется в творческом методе поэта в диалоге с русской литературой XIX в. Этот принцип проявляется во всех архитектонических формах әстетического объекта, прежде всего в субъектной сфере произведений.

У Г. Тукая немало стихотворений монологического характера, в которых «Я» поэта, занимающее отведенное для него место в иерархии ценностей, вполне традиционно. Это субъективный носитель «объективных» чувств и переживаний, в процессе приобщения к которым порой теряющий черты своей субъективности. Проповедуя некую общую грандиозную истину - гражданскую, нравственную, вселенскую, «Я» нередко становится неотличимым от «Мы». Аопущение, что «Я» как автономный и самоценный субъект может владеть истиной, дополняется представлением о посреднической функции автора, в котором индивидуально-творческое начало взаимодействует с традиционно-каноническим. Так, Г. Тукай нередко занимает скромную позицию ученика по отношению к авторитетным для него предшественникам - классикам русской литературы. Аирический герой стихотворения «Размышления одного татарского поэта» (1907) видит цель творчества в приближении к «первообразцам», данным классиками русской литературы: «Образцами мне Пушкин и Аермонтов служат...» (перевод Р. Морана) (Тукай, 1988: 128).

В лирике А. С. Пушкина появляется двухголосое и стилистически трехмерное слово, ориентированное на чужое (другое) слово (Бройтман, 2002: 110). Оно развертывает свою семантику в бесконечных столкновениях и преображениях различных смыслов, кодов, поворотов образов и тем. В ранних произведениях Г. Тукая доминирует «риторическое» (М. М. Бахтин) слово, т. е. одноголосое и объектное, непосредственно направленное на свой предмет и выражающее последнюю смысловую инстанцию говорящего (Бахтин, 1972: 340). В отличие от русских поэтов, воспринимающих язык как средство самовыражения творческой личности, в лирике Г. Тукая, последовательно проводящего мысль о том, что поэт владеет истиной в готовом виде и может транслировать ее читателям, складывается представление, что слово обладает неким независимым от конкретного человека существованием. Отсюда - обилие метонимических заменителей творческого дара, существующего в человеке как некая внеположная ему стихия, на которую лирический герой Г. Тукая пытается воздействовать, к которой обращается с вопросами, призывами. Например: «Огонь поэзии, гори в душе моей!» (перевод А. Чепурова) (Тукай, 1988: 153); «Отныне лги, мое перо, тумань глаза и вздор мели!» (перевод С. Северцева) (там же: 227).

В то же время психологическая конкретика, отражение духовного облика поэта и фактов его биографии, сложность и противоречивость изображаемых переживаний, ощущение внутренней причастности к движению национально-исторического бытия формируют лиризм особого типа - индивидуальный, личностный, создающий особую тональность каждого произведения поэта. С новыми эстетическими установками связано выдвижение на первый план субъективной значимости темы, личностно- 
го подхода к ее трактовке. Так, в стихотворении «К свободе» (1907), типологически сходном с одой А. С. Пушкина «Вольность», позиция лирического «Я», раскрывающего всю остроту противоречий современной ему действительности, поначалу лишена личностных примет. Но глубина отчаяния и боли человека, судьба которого неотделима от судьбы народа, выявляет субъективно-лирическую основу гневных обличений поэта.

В художественной концепции мира и А. С. Пушкина, и Г. Тукая господствует представление о законе и закономерностях, которые оба поэта ищут в просветительских теориях и традициях народно-национальной жизни. Аля Г. Тукая, как и для А. С. Пушкина, свобода - высшая ценность бытия, имеющая всеобъемлющий, универсальный смысл. Свобода - это двигатель истории, в которой лирический герой татарского поэта ищет пути к правде, справедливости, равноправию. В конкретно-исторических иллюстрациях своих положений Г. Тукай обращается к примерам из современной ему действительности, прямо соотнося их с событиями культурной мифологии. Образы и мотивы, восходящие к апокалиптически-эсхатологической парадигме: затмение Солнца, распад Ауны, трубный зов, падающие на землю звезды, улетающая от рода людского птица Симург, - образуют символическую перспективу, указывающую на разрушение и гибель упорядоченного космоса, торжество над ним хаотических сил.

Художественная система ряда стихотворений Г. Тукая 1905-1907 гг. вырастает на путях перекодировки в свете просветительских идей и концепций широко разработанного предшествующей традицией поэтического языка. Коранические и суфийские сюжеты, образы и мотивы прямо проецируются на реальные ситуации и события современной поэту общественно-политической действительности и наполняют их мифологическим подтекстом. Г. Тукай, с одной стороны, конкретизирует ситуацию, наполняя ее актуальными аллюзиями, с другой - органически вписывает в эсхатологическую проблематику и образную систему. Окружающий лирического героя мир со всеми присущими ему гротескными чертами включается в контекст божественного космоса - арену борьбы Аобра и Зла, Хаоса и Порядка, Света и Тьмы, демонических и небесных сил. Религиозно-мистические, эсхатологические темы и мотивы не только углубляют «просветительские» наставления и призывы Г. Тукая ракурсом иного измерения и видения событий. Между «тем» и «этим» мирами устанавливаются причинно-следственные связи. Наступление конца света ставится в прямую зависимость от реализации просветительских проектов и преобразований.

Суфийские образы и мотивы, аллюзии на произведения восточных авторов (Абу аль Маари, Аттара, Низами и др.), являясь әстетически имманентными факторами национально-культурной идентичности художественных текстов, переосмысливаются в соответствии с новыми идейно-творческими задачами автора и используются для изображения новых душевных состояний и устремлений личности, стремящейся к постижению своего внутреннего мира. Они указывают на исключительные по силе чувства и переживания лирического субъекта - всепоглощающую любовь к своему народу, любовь-страдание, любовь-вдохновение, творческое «горение», постижение истины и др. Например, для того чтобы передать силу и накал всепоглощающего чувства любви к своему народу, в стихотворении «К нации» (1906) поэт обращается к суфийским мотивам потери рассудка, сумасшествия, болезни-здоровья, одержимости любовью, отказа от своего «Я», метаморфозы субъекта и др.

Слияние и взаимопроникновение субъектных планов «Я» и «Аругого», их ценностных кругозоров в произведениях Г. Тукая обусловлены особенностями развития личного начала в татарской литературе этого периода (см: Нигматуллина, 1970: 55), 
а также характерной для данного типа культуры логикой формирования смысла: взаимно-однозначными соответствиями и взаимопереходами друг в друга единичного, психологически конкретного и всеобщего, родового, единого. Наряду с субъектным синкретизмом и различением «Я» и «Аругого», имеющим свои внутренние пределы, в лирике Г. Тукая можно констатировать рождение разных типов лирического субъекта - лирического «Я», лирического героя, героя ролевой лирики, субъектного неосинкретизма как результата самоидентификации «Я», наконец, «открытие автора и героя не как готовых и постоянных ролей в структуре произведения, а как перемежающихся, нестационарных состояний» (Бройтман, 2001: 300).

\section{ЖАНРОВОЕ СВОЕОБРАЗИЕ \\ АИРИЧЕСКИХ ПРОИЗВЕАЕНИЙ Г. ТУКАЯ}

\иризм нового типа и качественно новое «Я》 поэзии Г. Тукая подготавливают переход к новым принципам жанрового самоопределения. Жанр в классической восточной поэзии определяется прежде всего фиксированной и заданной композиционной структурой. Например, основополагающим принципом газеллы является смысловая самостоятельность бейтов, представляющих собой автономные по смыслу двустишия, связанные между собой по закону свободной ассоциации. С. Н. Бройтман подчеркивает, что эта жесткая и трудная форма не является чисто композиционной: «Она обретает свой художественный смысл только тогда, когда мы начинаем видеть в ней архитектоническую форму целого» (Бройтман, 2004: 194).

Г. Тукай соблюдает обязательные для газеллы способы композиционного построения (границы объема, определенный порядок повторяющихся рифм, редиф), вместе с тем он не использует характерную для этого жанра форму художественного завершения. Относительная автономность бейтов и ассоциативная свобода их сочетания подчиняются иным, чем в классической газелле, принципам интеграции. Так, в стихотворении «Разбитая надежда» (1910) мотив пути, поиск лирическим героем ценностей, нравственных ориентиров определяют не свойственное традиционной газелле линейное развертывание темы. В «Осенних ветрах» (1911) используется обязательное в произведениях данного жанра композиционное кольцо. Внутри этого кольца тема развивается по принципу смысловой и эмоциональной градации. В газеллах «О перо!» (1906), «Ауша» (1909) актуализируется коммуникативная стратегия заклинания (стремление воздействовать на мир, управлять силами бытия), формирующая архитектонику эстетического объекта и наиболее очевидно проявляющаяся на уровне ритмико-интонационной структуры текстов.

Г. Тукай сохраняет функциональную, тематическую и формальную определенность канонических жанров. Например, стихотворение «Пушкину» (1906) в литературоведении рассматривается как написанное в жанре оды (мадхии). Светоносные образы соответствуют жанровой эмоции восторга перед творениями великого русского поэта. Высокой тональности восхищения соответствует и принцип эмоциональной градации, когда каждый новый поворот темы, поднимая дух лирического «Я» вверх, способствует эмоциональному сгущению, концентрации высокого. Вместе с тем в оде-мадхие «Пушкину» появляется лирический герой, обладающий устойчивыми биографическими и психологическими чертами: он восхищается творениями великого русского писателя, выражает свое отношение к нему, размышляет о себе и о своем таланте.

Новый уровень самосознания поэта и характер его отношения к изображаемому определяют особый статус лирического субъекта в стихотворениях «Опозоренной 
татарской девушке» (1909), «Молодежь» (1910), «Светлой памяти Хусаина» (1912) и др. - наличие двойного угла зрения, взгляд на себя как на «Аругого». В марсии «Светлой памяти Хусаина» «Я» становится частью «Мы». Этим мотивируется появление иронии, которая, казалось бы, диссонирует с предыдущей тональностью высокого жанра марсии. «Мы» здесь - не поэтический прием, а обобщение определенных черт личности, носящее конкретный характер и отражающее стремление высказать истину о человеке и о себе самом. Так создается драматическая коллизия, которая усугубляется тем, что раскрывается в последнем бейте (в фиксированной сильной позиции), несущем в произведении повышенную идейно-смысловую нагрузку.

С многомерностью художественной ситуации в стихотворениях Г. Тукая связан закон полижанровости и полистилистики, организующий целостность произведений. Так, жанровая природа стихотворения «Молодежь» обусловлена сочетанием медитативности и исповедальности с иронией и инвективой. В «Разбитой надежде» (1910) элегическая модальность соединяется с драматической ситуацией одиночества, отчужденности лирического героя от мира и людей. В стихотворении «Надежда» драматическая коллизия блуждания во тьме развернута наряду с гетерономным ей мажорным, оптимистическим пафосом преодоления жизненных противоречий усилием воли, активностью духа.

Многочисленные послания представителям различных слоев татарского общества ( «Наборщикам газет», 1906; «Редактору», 1906; «Молодежи, организовавшей литературный вечер», 1906 и др.) восходят к традиции насихатов (произведений средневековой тюрко-татарской литературы, имеющих дидактическое содержание), формирующих жанровую стратегию этих произведений и определяющих их назидательно-парадигматическую интенцию. В них присутствует «Ты» («Вы»): газетные наборщики, редактор, молодежь, организовавшая литературный вечер, приятель, который просит совета, и др. Наличие собеседника влияет на композицию и стилистический облик текстов (используются обращения, разговорные речевые формы и т. п.), но ничего существенно не меняет в их структуре. Стихотворения остаются внутренне монологичными и реализуют одну смысловую позицию. Вместе с тем ораторские воскдицания совмещаются с лирическими признаниями, прямо высказанным дичным отношением к изображаемому. Так создается доверительная, исповедальная интонация, выявляющая глубинные основы мироощущения авторского «Я».

В стихотворениях «Пушкину», «Опозоренной татарской девушке», «Самоубийце» (1910), «Гению» (1913) «Ты» перестает быть формальным поводом для самовыражения и становится образом «Аругого», по отношению к которому лирический субъект дистанцируется и самоопределяется. Наконец, в «Мольбе» (1908), «Национальных мелодиях (1909), «Осенних ветрах» (1911), «Ааче» (1911) появляется «Аругой»носитель текстуально закрепленной точки зрения, отличающейся от видения мира лирическим героем. Субъект сознания может быть представлен в характерной для него речевой манере ( «Аача», вторая часть стихотворения «Мольба») или лишен ее (например, первая часть стихотворения «Мольба»).

\section{ПРИНЦИПЫ И ПРИЕМЫ \\ ПСИХОАОГИЧЕСКОГО ИЗОБРАЖЕНИЯ}

В диалоге с традициями русской, европейских и национально-восточных литератур в художественном методе Г. Тукая формируется и новый тип психологизма. Поэт широко использует синтетические методы и приемы психологического изображения, которые являются формой отражения устойчивого и изменчивого в душев- 
ной жизни лирического героя, индивидуально-неповторимого и типического, единичного и единого - категорий, между которыми устанавливаются свойственные данному типу культуры логико-семантические отношения равнозначности, равноценности, взаимно-однозначных соответствий. Эту функцию выполняют пейзажные описания, пространственно-временные образы и мотивы, обобщенные обозначения эмоций и др.

В то же время внутренний мир человека воспроизводится поэтом не только синтетически, но и аналитически. В стихотворениях «Надежда» (1908), «Ауша», «Неведомая душа» (1910), «Разбитая надежда», «Отчаяние» (1910) и в других душевная жизнь лирического героя изображается в полярной противоположности ее составляющих. Психологические антитезы, раскрывающие психологию человека нового времени во всей ее глубине, объемности и неисчерпаемой сложности, имеют восточно-национальные истоки: восходят к так называемому восточному психологизму страстей, которым отличалась газельная лирика (Халит, 1990: 101), суфийским парным символам, традициям классической арабской (творчество Аль Маари) и персидской (творчество Аттара) поэзии, которые, как установлено в литературоведении (Нигматуллина, 1997: 114-116; Хисамов, 2003: 20), оказали влияние на художественное мышление татарского поэта.

В то же время душевная раздвоенность, внутренняя противоречивость человека, борьба в нем противоположных начал осознаются не в отвлеченно-метафизическом свете (такова его доля, предопределенная свыше), но получают в лирике Г. Тукая конкретную социально-историческую, нравственно-психологическую мотивировку. В объяснении духовных устремлений личности, все более остро чувствующей свою зависимость от внешних обстоятельств, особенно значимыми оказываются социальнополитические и национально-исторические детерминанты. Аирический герой объективирован и выступает как часть «Мы»; его судьба, к постижению которой он движется через самопознание и самоанализ, приобретает обобщенный смысл.

Воссоздание душевной жизни человека в ее внутренних конфликтах и противоречиях, непрерывном столкновении мыслей и чувств драматизирует лирический текст, заряжая его энергией напряженного переживания царящей в мире дисгармонии. Аналитический психологизм, эмпирическая конкретность изображения, установление прямой зависимости сознания и психологии героя от общего состояния народно-национального бытия наполняют лирический текст эпическим содержанием. Таким образом, с принципами и приемами аналитического психологизма связаны художественно-содержательные особенности лирических произведений поэта, вбирающих в себя философско-этическую и социально-психологическую проблематику и синтезирующих принципы типизации, свойственные драматическому и эпическому родам литературы.

\section{ЗАКАЮЧЕНИЕ}

В работах М. М. Бахтина ( «Ответ на вопрос редакции “Нового мира”», «Из записей 1970-1971 годов») высказывается мысль о продуктивности для понимания смысловой глубины произведения дистанции, «вненаходимости» - «пространственной, временной, национальной» (Бахтин, 1979: 346). Позиция «вненаходимости» одной литературы по отношению к другой дает возможность иного, нового ее видения, недоступного взгляду «изнутри», позиции самонаблюдения.

Можно констатировать наличие в лирике Г. Тукая художественно-эстетических феноменов, структурно и функционально близких поэтике А. С. Пушкина, М. Ю. Аер- 
монтова и Н. А. Некрасова. На фоне этого структурно-функционального сходства, подтверждающего действенность традиций русской литературы в целом, явственно проступает различие между творчеством поэтов. В лирике Г. Тукая происходит переосмысление и переоценка с позиций иной аксиологической системы тем, идей, образов и мотивов поэзии А. С. Пушкина, М. Ю. Аермонтова и Н. А. Некрасова. Ауховносодержательный облик региональных художественных культур, присущие им процедуры смыслопорождения, национально-исторический и историко-литературный контексты, особенности индивидуально-авторского художественного видения поэтов определяют принципы организации субъектной сферы произведений, их жанровую природу, методы и приемы психологизма.

В стихотворениях Г. Тукая, А. С. Пушкина, М. Ю. Аермонтова, Н. А. Некрасова конкретно-исторический план содержания и смысла сопрягается с универсально-философским; социально-историческая и психологическая конкретность совмещается с общечеловеческими, глобальными и вселенскими категориями. Поэтика стихотворений русских поэтов связана с противопоставленностью и (или) иерархией этих аспектов художественного содержания. В произведениях Г. Тукая единичное и единое, преходящее и вечное, индивидуальное, социально-типовое и родовое принципиально располагаются на одном уровне, отражая характерную для данного типа культуры «процедуру» формирования смысла.

\section{СПИСОК АИТЕРАТУРЫ} $470 \mathrm{c}$.

Бахтин, М. М. (1972) Проблемы поэтики Аостоевского. М. : Художественная литература.

Бахтин, М. М. (1979) Эстетика словесного творчества. М. : Искусство. 424 с.

Бройтман, С. Н. (2001) Историческая поэтика. М. : Российский гос. гуманит. ун-т. 418 с.

Бройтман, С. Н. (2002) Тайная поэтика Пушкина. Тверь : Тверской гос. ун-т. 110 с.

Бройтман, С. Н. (2004) Историческая поэтика. М. : Изд. центр «Академия». 341 с.

Нигматуллина, Ю. Г. (1970) Национальное своеобразие әстетического идеала. Казань : Изд-во Казан. ун-та. 210 с.

Нигматуллина, Ю. Г. (1997) Типы культур и цивилизаций в историческом развитии татарской и русской литератур. Казань : Фэн. 189 с.

Пехтелев, И. Г. (1966) Тукай и русская литература. Казань : Татар. кн. изд-во. 182 с.

Тукай, Г. (1988) Стихотворения. $\Lambda$. : Советский писатель. 432 с.

Халит, Г. (1990) Многоликая лирика. Казань : Татар. кн. изд-во. 336 с.

Хисамов, Н. Ш. (2003) Тукайны төшену юлында: «Габдулла Тукай» энциклопедик сүзлек белешмәсенә материаллар. Казан : ТаРИХ. 80 б. (На татар. яз.).

Аата поступления: 28.02.2015 2.

\section{GABDULLA TUQAY'S LYRICAL WORKS IN THE INTERLITERARY CONTEXT \\ V. R. AMINEVA \\ (KAZAN (VoLGa REGION) FEDERAL UNIVERSITY)}

By studying the lyrical works of Tatar poet G. Tuqay (1886-1913) and those of 19th century Russian poets (A. S. Pushkin, M. Yu. Lermontov, N. A. Nekrasov), the article traces different types of dialogic relationship between the texts belonging to two national literatures. In these relationships, "one's own" may appear as a restructured version of the "alien", as its opposite, or as its cognate. We outline a generative function of interliterary dialogue as a factor influencing shifts in aesthetic consciousness and changes in artistic culture.

Staying in dialogue with 19 th century Russian literature, G. Tuqay's lyrics feature a new principle of art which is typical for the poetics of modality. This principle appears in all architectonic forms of 
an aesthetic object, but primarily in its subject. Tuqay's works show the birth of different types of the lyrical subject: the lyrical "I", the lyrical hero, the hero of role-based lyrics, and the subject's neo-syncretism stemming from self-identification. Forms of expression of the author's consciousness, as they appeared in the works of Russian and Tatar poets, defined genre and stylistic peculiarities of their texts. This new type of lyricism paved the way towards new principles of genre self-determination. In Tuqay's works, along with synthetic methods of describing man's inner world, analytical techniques of psychologism are widely used to recreate the inner world of modern man.

Thus, the dialogue between G. Tuqay and $19^{\text {th }}$ century Russian poets helps determine integrative processes in both literatures, on the one hand, and to reveal their national identity, on the other.

Keywords: Russian literature, Tatar literature, G. Tuqay, interliterary dialogue, lyric poetry, aesthetics of national art.

\section{REFERENCES}

Bakhtin, M. M. (1972) Problemy poetiki Dostoevskogo [Problems of Dostoevsky's poetics]. Moscow, Khudozhestvennaia literatura Publ. 470 p. (In Russ.).

Bakhtin, M. M. (1979) Estetika slovesnogo tvorchestva [Aesthetics of verbal art]. Moscow, Iskusstvo Publ. 424 p. (In Russ.).

Broitman, S. N. (2001) Istoricheskaia poetika [Historical poetics]. Moscow, Russian State University for the Humanities Publ. 418. (In Russ.).

Broitman, S. N. (2002) Tainaia poetika Pushkina [Pushkin's secret poetics]. Tver, Tver State University Publ. 110 p. (In Russ.).

Broitman, S. N. (2004) Istoricheskaia poetika [Historical poetics]. Moscow, Akademiia Publishing Center . 341 p. (In Russ.).

Nigmatullina, Yu. G. (1970) Natsional' noe svoeobrazie esteticheskogo ideala [National originality of the aesthetic ideal]. Kazan, Kazan University Publ. 210 p. (In Russ.).

Nigmatullina, Yu. G. (1997) Tipy kul'tur $i$ tsivilizatsii $v$ istoricheskom razvitii tatarskoi $i$ russkoi literatur [Types of cultures and civilizations in the historical development of the Tatar and Russian literatures]. Kazan, Fen Publ. 189, [2] p. (In Russ.).

Pekhtelev, I. G. (1966) Tukai i russkaia literatura [Tuqay and Russian literature]. Kazan, Tatar Book House. 182 p. (In Russ.). Russ.).

Tuqay, G. (1988) Stikhotvoreniia [Lyrical works]. Leningrad, Sovetskii pisatel' Publ. 432 p. (In

Khalit, G. (1990) Mnogolikaia lirika [The many-faced lyrics]. Kazan, Tatar Book House. 336 p. (In Russ.).

Khisamov, N. Sh. (2003) Tukainy tosheny iulynda: "Gabdulla Tukai» entsiklopedik syzlek beleshmosena materiallar [Understanding Tuqay's poetry: Materials for the Tuqay encyclopedia]. Kazan, TaRIKh Publ. 80 p. (In Tatar.).

Submission date: 28.02 .2015 .

Аминева Венера Рудалевна - доктор филологических наук, доцент, доцент кафедры русской литературы и методики преподавания Института филологии и межкультурной коммуникации Казанского (Приволжского) федерального университета. Адрес: 420008, Россия, г. Казань, ул. Кремлевская, д. 18. Тел.: +7 (843) 221-33-32. Эл. адрес: amineva1000@list.ru

Amineva Venera Rudalevna, Doctor of Philology, Associate Professor, Department of Russian Literature and Teaching Methods, Institute of Philology and Intercultural Communication, Kazan (Volga region) Federal University. Postal address: 18 Kremlevskaya St., 420008 Kazan, Russian Federation. Tel.: +7 (843) 221-33-32. E-mail: amineva1000@list.ru 